\title{
Comparison of maternal and fetal outcomes in gestational diabetes mellitus diagnosed either by oral glucose tolerance test or diabetes in pregnancy study group India
}

\author{
Somya Sinha*, Niranjan M. Mayadeo
}

Department of Obstetrics and Gynecology, King Edward Memorial Hospital, Mumbai, Maharashtra, India

Received: 31 July 2017

Revised: 08 August 2017

Accepted: 01 September 2017

\author{
*Correspondence: \\ Dr. Somya Sinha, \\ E-mail: somya_303@yahoo.co.in
}

Copyright: (c) the author(s), publisher and licensee Medip Academy. This is an open-access article distributed under the terms of the Creative Commons Attribution Non-Commercial License, which permits unrestricted non-commercial use, distribution, and reproduction in any medium, provided the original work is properly cited.

\begin{abstract}
Background: The optimal strategy for screening and diagnosis of Gestational Diabetes Mellitus (GDM) is still controversial and elusive. There is possibility of difference in maternal and fetal outcome depending on the diagnostic method used. This study throws light on the efficacy of two screening tests "Oral Glucose Tolerance Test" and "Diabetes in Pregnancy Study Group India" and to know maternal and fetal outcome in pregnancy complicated by GDM in Indian setting.

Methods: Depending on the diagnostic method used 100 GDM patients were divided in 2 groups: 1. OGTT, 2. DIPSI. Maternal outcomes were measured in terms of pregnancy induced hypertension, polyhydramnios, preterm labour, genital tract injury and methods of termination of pregnancy, gestational age at delivery. Congenital malformation, macrosomia, hypoglycemia, hyperbilirubinimia, respiratory distress, duration of NICU stay was studied in newborns.

Results: $22 \%$ of DIPSI group and $26 \%$ of OGTT group had PIH as comorbidity. Preterm delivery was noted in $22 \%$ of DIPSI group and $30 \%$ of OGTT group. $50 \%$ patients of both the groups underwent LSCS. No intrapartum complications were seen in $82 \%$ of patients. Malformations were noted in $18 \%$ of DIPSI group and $14 \%$ of OGTT group. In DIPSI group $14 \%$ of baby had macrosomia compared to $10 \%$ and in that of OGTT group.

In neonates, hypoglycaemia, respiratory distress syndrome and hyperbilirubinemia seen in $46.8 \%, 31 \%$ and $42.6 \%$ respectively in DIPSI group compared to $50 \%, 45.5 \%$ and $47.7 \%$ respectively in OGTT group.

Conclusions: No statistically significant difference was noted with respect to maternal and fetal outcomes between the two groups.
\end{abstract}

Keywords: DIPSI, Gestational diabetes mellitus, Oral glucose tolerance test

\section{INTRODUCTION}

There is a progressive increase in the incidence on diabetes mellitus all over the world and it is expected to increase by $165 \%$ by the year $2050 .{ }^{1}$ The increasing incidence of type 2 diabetes mellitus in the younger people in general has contributed to the increase in the incidence of Gestational Diabetes Mellitus (GDM). GDM is defined as carbohydrate intolerance of variable severity with onset or first recognition during pregnancy. ${ }^{1}$ It occurs when women's $\beta$-cell function is not able to overcome the antagonism created by anti-insulin hormone of pregnancy and increased fuel consumption required to provide for growing fetomaternal unit. 
Asian women are ethnically more prone to develop glucose intolerance compared to other ethnic groups. ${ }^{2}$ The relative risk of Indian women developing GDM is 11.3 times compared to White women. ${ }^{3}$

Major concern remains regarding the implications of GDM diagnosis on the pregnant woman and her baby and family, the effect of diagnosis on obstetric interventions. The perinatal, neonatal, maternal outcomes as well as overall health care costs can improve by early identification and treatment of GDM. ${ }^{4}$

The risk is higher in pregestational diabetes, but unrecognized and/or poorly managed gestational diabetes (GDM) may have similar consequences. ${ }^{5}$ As such GDM has implications beyond the index pregnancy, identifying two generations (mother and her offspring) at risk of future diabetes. Far-reaching implications can be seen by better identification and treatment of mothers and fetuses at risk. ${ }^{6}$

So, detection and management of GDM is very important. The optimal strategy for screening and diagnosis of GDM is still controversial. Universal versus. Selective screening is under debate.

American Diabetes Association (ADA) recommends two step procedures of 75 grams Oral Glucose Tolerance Test (OGTT) for screening and diagnosis. In India "Diabetes in Pregnancy Study Group India" (DIPSI) single step universal screening of all pregnant women between 24-28 weeks of gestation is being recommended due to high prevalence of GDM in India.

Diabetes in Pregnancy Study Group India (DIPSI), 75 gms oral glucose load in fasting state is given and after 2 hr venous blood sample is collected for estimating blood glucose level. ${ }^{7}$

\begin{tabular}{|llll|} 
& Normal & $\begin{array}{l}\text { IGT (impaired } \\
\text { glucose } \\
\text { tolerance) }\end{array}$ & $\begin{array}{l}\text { GDM } \\
\text { (Gestational } \\
\text { Diabetes } \\
\text { Mellitus) }\end{array}$ \\
\hline Fasting & $\begin{array}{l}<100 \\
\mathrm{mg} / \mathrm{dl}\end{array}$ & $110-125 \mathrm{mg} / \mathrm{dl}$ & $\geq 126 \mathrm{mg} / \mathrm{dl}$ \\
\hline $\begin{array}{l}\text { After } 2 \\
\text { hours }\end{array}$ & $\mathrm{mg} / \mathrm{dl}$ & $>140-199 \mathrm{mg} / \mathrm{dl}$ & $\geq 200 \mathrm{mg} / \mathrm{dl}$ \\
\hline
\end{tabular}

GDM is diagnosed if 2-hour plasma glucose is $\geq 140$ $\mathrm{mg} / \mathrm{dl}$. Advantages of DIPSI procedure are

- Pregnant woman need not be fasting

- Causes least disturbance in a pregnant woman's routine activities

- Serves as both screening and diagnostic procedure

- This single step procedure has been approved by the Ministry of Health, Government of India and also recommended by the WHO. ${ }^{8}$
The present study was undertaken in a tertiary care hospital to throw light on the efficacy of two screening tests and its relevance in Indian setting for knowing adverse maternal and fetal outcome in pregnancy complicated by GDM.

\section{METHODS}

The present study was carried out in a tertiary care hospital in Mumbai, India. After the approval of the Institutional Ethics Committee.

The data collection was performed over a period of 18 months. It was a comparative study which included both OPD patients and admitted pregnant patients.

\section{Inclusion criteria}

All patient with fasting blood sugar $95 \mathrm{mg} / \mathrm{dl}$ and above or post prandial blood sugar more than $140 \mathrm{mg} / \mathrm{dl}$ were enrolled in the study.

\section{Exclusion criteria}

Known cases of Diabetes Mellitus prior to pregnancy, irrespective whether on treatment or not.

\section{Study procedure}

- Proper consent of patient and relative for participation in study was taken.

- Patients were allotted in DIPSI and OGTT group alternately.

- Patients in the DIPSI Group were given $75 \mathrm{gms}$ of glucose at visit irrespective of fasting status and blood sample was collected after $2 \mathrm{hrs}$. The sample was sent to Clinical Chemistry Lab (CCL).

- GDM was diagnosed if blood sugar level of sample was $>140$ but $<200 \mathrm{mg} / \mathrm{dl}$.

- In the OGTT group Total of 4 Samples of blood were collected from patients: 1st sample after fasting of $>8$ hrs but $<14$ hrs.Following this $100 \mathrm{gms}$ of anhydrous glucose diluted in 1 glass of water was given to patient orally. Three samples were drawn after $1 \mathrm{hr}$, $2 \mathrm{hr}$ and $3 \mathrm{hr}$. GDM was diagnosed as per ADA criteria.

- All the above blood investigations were done in the biochemistry laboratory by the GOD-POD method. The reports of each case were recorded and analysed. The cut-offs for each glucose level were as follows: FBS $>92 \mathrm{mg} / \mathrm{dl}, 1$ Hour $>180 \mathrm{mg} / \mathrm{dl}$ and 2 Hour $>153 \mathrm{mg} / \mathrm{dl}$. If any one of the above 3 values was abnormal the patient was diagnosed as GDM.

\section{End point}

Once confirmed as GDM, 50 patients in each group were followed up throughout pregnancy till delivery in KEM Hospital, Mumbai, India and 7 days after that. 


\section{Outcome measures}

\section{Maternal outcome}

- Pregnancy Induced Hypertension

- Polyhydramnios(AFI $>=15)$

- Preterm delivery (<37 completed weeks)

- Methods of termination of pregnancy

- Genital tract injury

\section{Neonatal outcome}

- Macrosomia (baby wt>3500gms)

- Congenital malformation

- Hypoglycaemia (Capillary blood glucose <=2.6 mmol)

- Hyperbilirubinimia

- Respiratory distress

- Duration of NICU stay

\section{Statistical analysis}

Data collected were both qualitative data eg. maternal outcome and quantitative data eg. gestational age. The results were compared by $\mathrm{Chi}$ square test. $\mathrm{P}$ value of $<0.05$ was considered significant for the study.

\section{RESULTS}

Table 1: Comparison of incidence of pregnancy induced hypertension in DIPSI group and OGTT group.

\begin{tabular}{|c|c|c|c|}
\hline \multicolumn{4}{|c|}{ Test } \\
\hline Preeclampsia & & DIPSI & OGTT \\
\hline \multirow[t]{2}{*}{$\mathrm{N}$} & Count & 39 & 37 \\
\hline & $\%$ within Test & $78.00 \%$ & $74.00 \%$ \\
\hline \multirow[t]{2}{*}{$\mathrm{Y}$} & Count & 11 & 13 \\
\hline & $\%$ within Test & $22.00 \%$ & $26.00 \%$ \\
\hline \multirow[t]{3}{*}{ Total } & Count & 50 & 50 \\
\hline & $\%$ within Test & $100.00 \%$ & $100.00 \%$ \\
\hline & Value & df & $\mathrm{p}$-value \\
\hline $\begin{array}{l}\text { Pearson Chi- } \\
\text { Square }\end{array}$ & 0.219 & 1 & 0.64 \\
\hline
\end{tabular}

$22 \%$ patients in DIPSI group and $26 \%$ patients in OGTT group has pregnancy complicated by PIH. But majority patients had no PIH in present pregnancy (DIPSI 78\% versus OGTT 74\%) No statistically significant difference was seen between both groups $(\mathrm{p}=0.64)$.

Approximately equal number of cases of polyhydramnios were detected by both tests DIPSI $12 \%$ versus OGTT $10 \%$. Statistically significant difference was not seen $(\mathrm{p}=0.743)$.

Preterm delivery was seen in $22 \%$ patient of DIPSI group and $30 \%$ of OGTT group. $76 \%$ of patient of DIPSI group compared to $66 \%$ that of OGTT group had term delivery.
No post-dated delivery in both groups was seen. Difference is not statistically significant $(\mathrm{p}=0.522)$.

Table 2: Comparison of incidence of polyhydramnios in DIPSI group and OGTT group.

\begin{tabular}{|llll|}
\hline AFI & Test & DIPSI & OGTT \\
\hline$<15$ & Count & 44 & 45 \\
\hline & \% within Test & $88.00 \%$ & $90.00 \%$ \\
\hline$>15$ & $\begin{array}{l}\text { Count } \\
\text { \% within Test }\end{array}$ & 6 & 5 \\
\hline Total & $12.00 \%$ & $10.00 \%$ \\
\hline & \% within Test & $100.00 \%$ & $100.00 \%$ \\
\hline $\begin{array}{l}\text { Pearson } \\
\text { Chi- } \\
\text { Square }\end{array}$ & Value & df & p-value \\
\hline
\end{tabular}

Table 3: Comparison of gestational age at confinement in DIPSI group and OGTT group.

\begin{tabular}{|c|c|c|c|}
\hline $\begin{array}{l}\text { Gestational } \\
\text { age at }\end{array}$ & Test & & \\
\hline $\begin{array}{l}\text { Confinement } \\
\text { (wks) }\end{array}$ & & DIPSI & OGTT \\
\hline \multirow[t]{2}{*}{0 to 27} & Count & 1 & 2 \\
\hline & $\%$ within Test & $2.00 \%$ & $4.00 \%$ \\
\hline \multirow[t]{2}{*}{28 to 36} & Count & 11 & 15 \\
\hline & $\%$ within Test & $22.00 \%$ & $30.00 \%$ \\
\hline \multirow[t]{2}{*}{37 to 40} & Count & 38 & 33 \\
\hline & $\%$ within Test & $76.00 \%$ & $66.00 \%$ \\
\hline \multirow[t]{3}{*}{ Total } & Count & 50 & 50 \\
\hline & $\%$ within Test & $100.00 \%$ & $100.00 \%$ \\
\hline & Value & df & p-value \\
\hline $\begin{array}{l}\text { Pearson Chi- } \\
\text { Square }\end{array}$ & 1.301 & 2 & 0.522 \\
\hline
\end{tabular}

Table 4: Comparison of outcome of pregnancy in DIPSI group and OGTT group.

\begin{tabular}{|llll|}
\hline Outcome & & DIPSI & OGTT \\
\hline $\begin{array}{l}\text { Induction of } \\
\text { labour }\end{array}$ & Count & 3 & 8 \\
\hline & $\%$ within Test & $6.00 \%$ & $16.00 \%$ \\
\hline LSCS & Count & 25 & 25 \\
\hline MTP & \% within Test & $50.00 \%$ & $50.00 \%$ \\
\hline & Count & 1 & 0 \\
\hline Outlet forcep & \% within Test & $2.00 \%$ & $0.00 \%$ \\
\hline & Count & 1 & 3 \\
\hline Spontaneous & Count & 20 & 14 \\
\hline & $\%$ within Test & $40.00 \%$ & $28.00 \%$ \\
\hline Total & Count & 50 & 50 \\
\hline & $\%$ within Test & $100.00 \%$ & $100.00 \%$ \\
\hline & Value & df & p-value \\
\hline $\begin{array}{l}\text { Pearson Chi- } \\
\text { Square }\end{array}$ & 5.332 & 4 & 0.255 \\
\hline
\end{tabular}


$50 \%$ patients of both the groups underwent LSCS. $40 \%$ patients of DIPSI group compared to $28 \%$ of that of OGTT group delivered due to spontaneous onset of labour. MTP was performed only one patient of DIPSI group and none in OGTT group. Difference was not statistically significant $(\mathrm{p}=0.255) .2 \%$ patient of DIPSI group compared to $6 \%$ in OGTT group had outlet forcep delivery.

Table 5: Comparison of intrapartum complications in DIPSI group and OGTT group.

\begin{tabular}{|lllll|}
\hline Complications & Test & DIPSI & OGTT & Total \\
\hline Adhesion & Count & 2 & 3 & 5 \\
\hline & $\%$ within Test & $4.00 \%$ & $6.00 \%$ & $5.00 \%$ \\
\hline Genital injury & Count & 4 & 4 & 8 \\
\hline \\
\hline Shoulder dystocia & $\%$ within Test & $8.00 \%$ & $8.00 \%$ & $8.00 \%$ \\
\hline & Count & 3 & 2 & 5 \\
\hline No & \% within Test & $6.00 \%$ & $4.00 \%$ & $5.00 \%$ \\
\hline Total & Count & 41 & 41 & 82 \\
\hline & Count & $82.00 \%$ & $82.00 \%$ & $82.00 \%$ \\
\hline & $\%$ within Test & 50 & 50 & 100 \\
\hline Pearson Chi-Square & & $100.00 \%$ & $100.00 \%$ & $100.00 \%$ \\
\hline
\end{tabular}

No intrapartum complication was seen in equal number $(n=41) 82 \%$ of patients in both groups. Genital injury was same in both groups $8 \%(n=4)$ of both group. $6 \%(n=3)$ patients of DIPSI group compared to $4 \%(n=2)$ that of OGTT had shoulder dystocia. Difference was not statistically significant $(\mathrm{p}=0.94)$

Table 6: Comparison of weight of baby in DIPSI group and OGTT group.

\begin{tabular}{|c|c|c|c|}
\hline \multicolumn{4}{|c|}{ Test } \\
\hline $\begin{array}{l}\text { Baby wt } \\
\text { (gms) }\end{array}$ & & DIPSI & OGTT \\
\hline \multirow[t]{2}{*}{$<2000$} & Count & 6 & 9 \\
\hline & $\%$ within Test & $12.00 \%$ & $18.00 \%$ \\
\hline \multirow[t]{2}{*}{2000 to 3500} & Count & 37 & 36 \\
\hline & $\%$ within Test & $74.00 \%$ & $72.00 \%$ \\
\hline \multirow[t]{2}{*}{$>3500$} & Count & 7 & 5 \\
\hline & $\%$ within Test & $14.00 \%$ & $10.00 \%$ \\
\hline \multirow[t]{3}{*}{ Total } & Count & 50 & 50 \\
\hline & $\%$ within Test & $100.00 \%$ & $100.00 \%$ \\
\hline & Value & $\mathrm{df}$ & p-value \\
\hline $\begin{array}{l}\text { Pearson Chi- } \\
\text { Square }\end{array}$ & 1.459 & $4 \quad 0.834$ & \\
\hline
\end{tabular}

Macrosomia was seen in $14 \%(n=7)$ of baby of DIPSI group and $10 \%(n=5)$ of OGTT group. Baby weight less than $2 \mathrm{~kg}$ was seen in $12 \%(\mathrm{n}=6)$ of DIPSI group and $18 \%$ $(n=9)$ of OGTT group. 2 babies from each group were term IUGR. One patient from DIPSI group had MTP. This baby was admitted in NICU and had greater incidence of hypoglycemia. Difference was not statistically significant $(\mathrm{p}=0.834)$
Table 7: Comparison of malformations in baby in DIPSI and OGTT group.

\begin{tabular}{|lllll|}
\hline Malformation & & DIPSI & OGTT & Total \\
\hline $\mathrm{N}$ & $\mathrm{N}$ & 41 & 43 & 84 \\
\hline $\mathrm{Y}$ & $\%$ & $82.00 \%$ & $86.00 \%$ & $84.00 \%$ \\
\hline & $\mathrm{N}$ & 9 & 7 & 16 \\
\hline Total & $\%$ & $18.00 \%$ & $14.00 \%$ & $16.00 \%$ \\
\hline & $\mathrm{N}$ & 50 & 50 & 100 \\
\hline & $\%$ & $100.00 \%$ & $100.00 \%$ & $100.00 \%$ \\
\hline $\begin{array}{l}\text { Pearson Chi- } \\
\text { Square }\end{array}$ & Value & $\mathrm{df}$ & $\mathrm{p}$-value & \\
\hline
\end{tabular}

Table 8: Comparison of incidence of hypoglycemia in DIPSI group and OGTT group.

\begin{tabular}{|l|lll|}
\hline Hypoglycemia & Test & DIPSI & OGTT \\
\hline $\mathrm{N}$ & Count & 25 & 22 \\
\hline & $\begin{array}{l}\text { \% within } \\
\text { Test }\end{array}$ & $53.20 \%$ & $50.00 \%$ \\
\hline Y & Count & 22 & 22 \\
\hline & $\begin{array}{l}\text { \% within } \\
\text { Test }\end{array}$ & $46.80 \%$ & $50.00 \%$ \\
\hline Total & Count & 47 & 44 \\
\hline & $\begin{array}{l}\text { \% within } \\
\text { Test }\end{array}$ & $100.00 \%$ & $100.00 \%$ \\
\hline $\begin{array}{l}\text { Pearson Chi- } \\
\text { Square }\end{array}$ & 0.093 & df & p-value \\
\hline
\end{tabular}


Incidence of malformations were comparable $18 \%(\mathrm{n}=9)$ in DIPSI group and $14 \%(n=7)$ of OGTT group.

NTD was seen in 4 babies of DIPSI group compared to 2 babies of OGTT group. 2 babies of DIPSI group and 3 of OGTT group had VSD. 1 baby from each group had renal anomaly. Difference was not statistically significant $(\mathrm{p}=0.585)$.

$46.8 \%$ of babies of DIPSI group and $50 \%$ that of OGTT group developed hypoglycemia. Difference is not statistically significant $(\mathrm{p}=0.761)$

Table 9: Comparison of incidence of respiratory distress In DIPSI group and OGTT group.

\begin{tabular}{|l|lll|}
\hline $\begin{array}{l}\text { Respiratory } \\
\text { distress }\end{array}$ & DIPSI & OGTT \\
\hline $\mathrm{N}$ & Count & 32 & 24 \\
\hline & $\begin{array}{l}\text { \% within } \\
\text { Test }\end{array}$ & $68.10 \%$ & $54.50 \%$ \\
\hline $\mathrm{Y}$ & Count & 15 & 20 \\
\hline & $\begin{array}{l}\text { \% within } \\
\text { Test }\end{array}$ & $31.90 \%$ & $45.50 \%$ \\
\hline Total & Count & 47 & 44 \\
\hline & $\begin{array}{l}\text { \% within } \\
\text { Test }\end{array}$ & $100.00 \%$ & $100.00 \%$ \\
\hline $\begin{array}{l}\text { Pearson Chi- } \\
\text { Square }\end{array}$ & Value & $\mathrm{df}$ & p-value \\
\hline
\end{tabular}

$31 \%(n=15)$ cases of DIPSI group compared to $45.50 \%$ $(n=20)$ that of OGTT group developed Respiratory Distress Syndrome. Difference is not statistically significant $(\mathrm{p}=0.185)$.

Table 10: Comparison of incidence of hyperbilirubinimia in DIPSI group and OGTT group.

\begin{tabular}{|llll|}
\hline Hyperbilirubinimia & & DIPSI & OGTT \\
\hline $\mathrm{N}$ & Count & 27 & 23 \\
\hline & $\begin{array}{l}\text { T } \\
\text { within } \\
\text { Test }\end{array}$ & $57.40 \%$ & $52.30 \%$ \\
\hline $\mathrm{Y}$ & Count & 20 & 21 \\
\hline & $\%$ & & \\
& $\begin{array}{l}\text { within } \\
\text { Test }\end{array}$ & $42.60 \%$ & $47.70 \%$ \\
\hline Total & Count & 47 & 44 \\
\hline & $\%$ & & \\
\hline & within & $100.00 \%$ & $100.00 \%$ \\
\hline Test & & \\
\hline Pearson Chi-Square & Value & df & p-value \\
& 0.246 & 1 & 0.62 \\
\hline
\end{tabular}

Hyperbilirubinimia developed in $42.60 \%(\mathrm{n}=20)$ cases of DIPSI group compared to $47.70 \%(n=21)$ that of OGTT group. Difference is not statistically significant. $(\mathrm{p}=0.62)$

Table 11: Comparison of duration of NICU stay in DIPSI group and OGTT group.

\begin{tabular}{|llll|}
\hline $\begin{array}{l}\text { NICU stay } \\
\text { (days) }\end{array}$ & & DIPSI & OGTT \\
\hline 0 & Count & 10 & 12 \\
\hline & $\%$ within Test & $20.00 \%$ & $24.00 \%$ \\
\hline 1 to 4 & Count & 29 & 22 \\
\hline & $\%$ within Test & $58.00 \%$ & $44.00 \%$ \\
\hline$>4$ & Count & 8 & 13 \\
\hline & $\%$ within Test & $16.00 \%$ & $26.00 \%$ \\
\hline NA & Count & 3 & 3 \\
\hline Total & Count within Test & $6.00 \%$ & $6.00 \%$ \\
\hline & $\%$ within Test & $100.00 \%$ & $100.00 \%$ \\
\hline & Value & df & p-value \\
\hline $\begin{array}{l}\text { Pearson Chi- } \\
\text { Square }\end{array}$ & 1.245 & 3 & 0.742 \\
\hline
\end{tabular}

Infants of GDM mothers managed on diet i.e. $20 \%$ $(n=10)$ cases of DIPSI group and $24 \%(n=12)$ cases of OGTT group did not require NICU admission. Prolong admission for more than 4 days was required by $16 \%$ $(n=8)$ cases of DIPSI group and $26 \%(n=13)$ of OGTT group. Majority of cases of both groups (DIPSI 58\% vs OGTT $44 \%$ ) were admitted for 1 to 4 days. $(\mathrm{p}=0.742)$

\section{DISCUSSION}

The present study was undertaken in a tertiary care hospital in Mumbai, India after the approval of Institutional Ethics Committee. The main aim was to compare maternal and fetal outcomes in cases diagnosed as Gestational diabetes mellitus either by "Oral Glucose Tolerance Test"'(OGTT) or "Diabetes in Pregnancy Study Group India" (DIPSI) and a short follow-up of these cases post-partum. 1602 antenatal patients during the study period of 18 months were screened for FBS and PLBS at any gestational age.

Patients having fasting blood sugar (FBS) $95 \mathrm{mg} / \mathrm{dl}$ and above or post prandial blood sugar (PLBS) $140 \mathrm{mg} / \mathrm{dl}$ and above were taken after proper consent. Out of these patients 28 patients were known type 2 diabetics and were not included in the present study. A total of 175 patients were subjected to OGTT and DIPSI test alternatively. 102 patients were diagnosed as gestational diabetes mellitus according to ADA diagnostic criteria (any one reading of fasting > 92mg/dl, 1 hour > $180 \mathrm{mg} / \mathrm{dl}, 2$ hour $>153 \mathrm{mg} / \mathrm{dl}) .84$ patients were followed till 7 days after birth. 16 patients referred from other hospital who were diagnosed as GDM by same criteria were also included. 


\section{Pregnancy induced hypertension}

In the study, be Saxena et al, the incidence of PIH was $40 \% .{ }^{9}$ According to Wahi et al in Jammu, India it was $6.45 \% .{ }^{10}$ Xiong et al reported mothers with GDM were at increased risk of presenting with pre-eclampsia as they have similar risk profile. ${ }^{11}$

In the present study, 22\% patients in DIPSI group and $26 \%$ patients in OGTT group has pregnancy complicated by both GDM and PIH. But majority patients had no PIH in present pregnancy (DIPSI 78\% versus OGTT 74\%) No statistically significant difference was seen between both groups $(p=0.64)$. Thus, there is an association between $\mathrm{PIH}$ and GDM and early diagnosis and initiation of treatment should be done to improve the outcome.

\section{Polyhydramnios}

Bhat et al found a $14.7 \%$ incidence of polyhydramnios versus $2.7 \%$ in controls. ${ }^{12}$ In the present study, approximately equal number of cases of GDM was detected by both tests DIPSI $12 \%(n=6)$ vs OGTT $10 \%$ $(n=5)$. Polyhydramnios in diabetes is probably related to fetal polyuria due to fetal hyperglycemia.

Polyhydramnios complicating GDM pregnancies is associated with higher perinatal mortality and morbidity rates than pregnancies with normal amniotic fluid. ${ }^{9}$

\section{Preterm delivery}

In a study by Mahalakshmi et al MM in South India, 19\% were preterm live birth. ${ }^{13}$ Saxena et al reported a $12 \%$ incidence of preterm babies.

In the present study, Preterm delivery was seen in $22 \%$ patient of DIPSI group and $30 \%$ of OGTT group. Preterm births in present study were attributed to premature preterm rupture of membranes, preterm labour and early induction in cases of severe preeclampsia. No pregnancy was continued till postdatism as chances of IUFD are increased.

\section{Mode of termination}

According to Kale et al, the incidence of LSCS in patients with GDM was found to be $60 \% .{ }^{14}$ According to Saxena et al, caesarean was done in $42 \%$ cases. ${ }^{9}$ Wahi et al reported $22.58 \%$ incidence of caesarean. ${ }^{10}$ Cassey et alreported caesarean section rates of $30 \%$ in women with GDM. ${ }^{15}$ A study in Denmark by Jenson et al, and in Sweden by Aberg et al also found an increased rate of caesarean section in patients with GDM. ${ }^{16,17}$

Kraiem et al found that rate of caesarean section significantly increased among the patients who delivered after labour induction as compared to those who went into spontaneous labour. ${ }^{18}$ In the present study, $50 \%$ patients of both the groups underwent LSCS. $40 \%$ patients of DIPSI group compared to $28 \%$ of that of OGTT group delivered due to spontaneous onset of labour. Difference was not statistically significant $(\mathrm{p}=0.255)$.

Labour was induced in most patients at about 38 weeks in this study. A part of patients induced vaginally underwent LSCS in view of non-progress of labour or fetal distress or meconium stained amniotic fluid in first stage of labour while elective caesarean sections were performed for indications like previous 2 LSCS, previous LSCS not willing for VBAC, cephalopelvic disproportion, bad obstetric history, breech presentation, placenta previa, precious pregnancy.

MTP was performed in only one patient of DIPSI group and none in OGTT group as anencephaly was detected before 20 weeks of gestation. $2 \%$ patient of DIPSI group compared to $6 \%$ in OGTT group had outlet forceps delivery. In both group, statistically significant difference was not $(\mathrm{p}=0.225)$.

\section{Genital injury}

Genital injury was seen $8 \%(n=4)$ of both group. $6 \%$ $(n=3)$ patients of DIPSI group compared to $4 \%(n=2)$ that of OGTT had shoulder dystocia. Statistically significant difference was not seen in both groups $(p=0.94)$ in terms of intrapartum complications. Vaginal laceration and periurethral tear was seen.

\section{Macrosomia}

In the Polish study by Cypryk et al, history of big baby (macrosomia) was present in $11 \%$ of patients. ${ }^{19}$ Najafian et al found incidence of macrosomia in $9 \%$ cases. ${ }^{20}$ Balaji et al found incidence of macrosomia in India as $9.9 \%{ }^{21}$

In present study, macrosomia was seen in $14 \%$ of baby of DIPSI group and $10 \%$ of OGTT group. Difference was not statistically significant. Gestational diabetes, maternal obesity (BMI), maternal age and positive history of previous macrosomia were the major risk factors for macrosomia which were compared with the normal weight infant groups.

Fetal macrosomia is a common adverse infant outcome of GDM if unrecognized and untreated in time. For the infant, macrosomia increases the risk of shoulder dystocia, postpartum hemorrhage and genital injury.

\section{Malformed baby}

According to Shefali et al $1.4 \%$ babies had congenital anomalies. ${ }^{22}$ Saxena et al reported congenital anomalies in $10 \%$ of babies. ${ }^{9}$

In present study, malformed baby was seen in $18 \%(n=9)$ in DIPSI group and $14 \%(n=7)$ of OGTT group. 
Statistically significant difference between two groups was not seen $(\mathrm{p}=0.585)$.

Variation is seen due to blood sugar levels during period of organogenesis. Neural tube defect, ventricular septal defect and renal malformation were seen. IUFD occurred in 2 patients of DIPSI group while number in OGTT group was 3 . These were seen in patients who had poor compliance and poorly controlled blood sugars

\section{Hypoglycemia}

Mahalakshmi et al reported hypoglycemia in $10.4 \%$ patients. ${ }^{13}$ In the present study, $46.8 \%$ of babies of DIPSI group and 50\% that of OGTT group developed hypoglycemia. Difference was not statistically significant $(\mathrm{p}=0.761)$.

\section{Respiratory distress}

Mitanchez in literature review found there was limited data from which to report on the prevalence of respiratory distress in infants born to mothers with GDM. ${ }^{23}$

$31 \%(n=15)$ cases of DIPSI group compared to $45.50 \%$ $(n=20)$ that of OGTT group developed respiratory distress syndrome. Difference was not statistically significant $(\mathrm{p}=0.185) .8$ newborns of DIPSI group and 12 from OGTT group who underwent LSCS developed transient tachypnoea of newborn. 3 newborns of DIPSI group and 2 of OGTT group received surfactant.

\section{Hyperbilirubinimia}

In the present study, hyperbilirubinimia developed in $42.60 \%(n=20)$ cases of DIPSI group compared to $47.70 \%(n=21)$ that of OGTT group. Difference was not statistically significant $(\mathrm{p}=0.62) .20 \% \quad(\mathrm{n}=10)$ cases of DIPSI group and $24 \%(n=12)$ cases of OGTT group did not require NICU admission. Majority were baby of GDM mothers who had blood sugar well controlled on diet.

\section{Duration of NICU stay}

Malak et al noted the incidence of neonatal intensive care admission was $4.9 \%$. The mean length of stay in the NICU was 16 days. The commonest cause of neonatal NICU admission was hyperbilirubinimia $(41.2 \%) .{ }^{24}$

Majority of cases of both groups (DIPSI 58\% vs OGTT $44 \%$ ) were admitted for 1 to 4 days. These were babies of GDM mothers who were managed on insulin, OHA were admitted in NICU prophylactically for monitoring. Asymptomatic newborns were discharged after 1 day.

Prolong NICU admission of more than 4 days were seen in babies who developed respiratory distress, hypoglycemia or hyperbilirubinimia.
These comprised $16 \%(\mathrm{n}=8)$ cases of DIPSI group and $26 \%(n=13)$ of OGTT group. No statistically significant difference $(p=0.742)$ was seen in duration of NICU stay of both groups.

\section{CONCLUSION}

The prevalence of GDM seen was $5.09 \%$ which is comparable to other parts of India. Both test diagnosed GDM in different period without much difference. No statistically significant difference was observed between all the parameters of maternal and fetal outcomes between the two tests in the present study. It is concluded that fetal and maternal outcome is independent of method of screening and depends on maternal glycemic control during pregnancy.

GDM is a window of opportunity for prevention of diabetes in future life but this opportunity provided by GDM can be utilized only if optimal medical and obstetric care is provided to the antenatal patient with GDM. Optimal management of GDM remains a challenge for the obstetricians and endocrinologists. Most cases of GDM can be managed by lifestyle and dietary modification, but when required, pharmacological treatment becomes necessary. Team effort on part of obstetricians, endocrinologists and neonatologist is required to manage GDM effectively, not only for the present generation but also for the generations to come. We should try our Medicare system to convert "the diabetes capital of the world" into "the diabetes care capital of the world".

\section{Funding: No funding sources \\ Conflict of interest: None declared \\ Ethical approval: Not required}

\section{REFERENCES}

1. Cunningham FGy, Leveno KJ, Bloom SL, Hauth JC, Rouse DJ, Spong CY. Diabetes. In, Williams Obstetrics, 23rd Edition. New York, Mc Graw Hill Medical Publisher. 2010;1104-25.

2. Beischer NA, Oats JN, Henry OA, Sheedy MT, Walstab JE. Incidence and severity of gestational diabetes mellitus according to country of birth in women living in Australia. Diabetes. 1991;40 Suppl 2:35-8.

3. Dornhost A, Paterson CM, Nicholls JS, Wadsworth J, Chiu DC, Elkeles RS, et al. High prevalence of GDM in women from ethnic minority groups. Diabetic Med. 1992;9:820-2.

4. American College of Obstetricians and Gynecologists Committee on Practice BulletinsObstetrics. ACOG Practice Bulletin, authors. Clinical management guidelines for obstetriciangynecologists. Number 30, September 2001 Gestational diabetes. Obstet Gynecol. 2001;98:52538 . 
5. Mitanchez D, Yzydorczyk C, Siddeek B, Boubred F, Benahmed M, Simeoni U. The offspring of the diabetic mother-short-and long-term implications. Best Practice Res Clinic Obstetr Gynaecol. 2015;29(2):256-69.

6. Barbour LA. Unresolved controversies in gestational diabetes: implications on maternal and infant health. Curr Opin Endocrinol Diabetes Obes. 2014 Aug;21(4):264-70.

7. Seshiah V, Das AK, Balaji V, Joshi SR, Parikh MN, Gupta S. Gestational diabetes mellitus-guidelines. JAPI. 2006;54:622-2.

8. Government of India, Ministry of Health and Family Welfare, Nirman Bhavan, New Delhi. (DO No. M12015/93/2011-MCH/2011).

9. Saxena P, Tyagi S, Prakash A, Nigam A. Pregnancy Outcome of Women with Gestational Diabetes in a Tertiary Level Hospital of North India Indian J Community Med. 2011;36(2):120-3.

10. Wahi, Prevalence of Gestational Diabetes Mellitus (GDM) and its Outcomes in Jammu Region, J Assoc Physicians India, 2011;59:227-30.

11. Xiong X, Saunders LD, Wang FL, Demianczuk NN. Gestational diabetes mellitus: Prevalence, risk factors, maternal and infant outcomes. Int J Gynaecol Obstet. 2001;75:221-8.

12. Bhat M, Ramesha KN, Sarma SP, Sangeetha Menon SC, Kumar G. Determinants of gestational diabetes mellitus: A case control study in a district tertiary care hospital in south India. Internat $\mathbf{J}$ Diabetes in developing countries. 2010;30(2):91

13. Mahalakshmi MM. Clinical profile, outcomes, and progression to type 2 diabetes among Indian women with gestational diabetes mellitus seen at a diabetes center in south India. Indian $\mathbf{J}$ Endocrinol Metab. 2014;18(3):400-6.

14. Yajnik CS, Kale SD, Kulkarni SR, Meenakumari K, Joglekar AA, Khorsand $\mathrm{N}$, et al. High risk of diabetes and metabolic syndrome in Indian women with gestational diabetes mellitus. Diabetes Medicine 2004;21:1257-9.

15. Casey BM, Lucas MJ, McIntire DD, Leveno KJ. Pregnancy outcomes in women with gestational diabetes compared with the general obstetric population. Obstet Gynecol. 1997;90:869-73.
16. Jensen DM, Damm P, Sorensen B, Molsted-Pedersen L, Westergaard JG, Klebe J, et al. Clinical impact of mild carbohydrate intolerance in pregnancy: a study of 2904 nondiabetic Danish women with risk factors for gestational diabetes mellitus. Am J Obstet Gynecol. 2001;185:413-9.

17. Aberg A, Rydhstroem H, Frid A. Impaired glucose tolerance associated with adverse pregnancy outcome: a population-based study in southern Sweden. Am J Obstet Gynecol. 2001;184:77-83.

18. Kraïem J, Chiha N, Bouden B, Ounaïssa F, Falfoul A. The delivery of macrosomic infants weighing $4500 \mathrm{~g}$ and more. A report of 61 cases. La Tunisie Medicale. 2004;82(7):656-61.

19. Cypryk K, Szymczak W, Czupryniak L, Sobczak M, Lewiński A. Gestational diabetes mellitus-an analysis of risk factors. Endokrynologia Polska. 2008;59(5):393-7.

20. Najafian $M$, Cheraghi $M$. ccurrence of Fetal Macrosomia Rate and Its Maternal and Neonatal Complications: A 5-Year Cohort Study, ISRN Obstet and Gynecol. 2012:2012:5.

21. Balaji V, Anjalakshi C and Seshiah V. Diagnosis of gestational diabetes mellitus in Asian-Indian women. Indian J Endocrinol Metab. 2011;15(3):187-90.

22. Shefali AK, Pregnancy Outcomes in Pre-gestational and Gestational Diabetic Women in Comparison to Non-diabetic Women A Prospective Study in Asian Indian Mothers, J Assoc Physicians India. 2006;54:613-8.

23. Mitanchez D. Foetal and neonatal complications in gestational diabetes: perinatal mortality, congenital malformations, macrosomia, shoulder dystocia, birth injuries, neonatal complications. Diabetes Metab. 2010;36:617-27.

24. Malak M. Al-Hakeem, pregnancy outcome of gestational diabetic mothers: experience in a tertiary center. J Fam Community Med. 2006;13(2):55-9.

Cite this article as: Sinha S, Mayadeo NM. Comparison of maternal and fetal outcomes in gestational diabetes mellitus diagnosed either by oral glucose tolerance test or diabetes in pregnancy study group India. Int J Reprod Contracept Obstet Gynecol 2017;6:4526-33. 